\title{
Comparison of the efficacy of intradermal injected tranexamic acid vs hydroquinone cream in the treatment of melasma
}

This article was published in the following Dove Medical Press journal: Clinical, Cosmetic and Investigational Dermatology

\author{
Nader Pazyar ${ }^{\prime}$ \\ Reza Yaghoobi' \\ Maryam Zeynalie ${ }^{2}$ \\ Samin Vala ${ }^{2}$ \\ 'Dermatology Department, Ahvaz \\ Jundishapur University of Medical \\ Science, Ahvaz, Iran; ${ }^{2}$ Dermatology \\ Department, Emam Hospital, School \\ of Medicine, Ahvaz University of \\ Medical Science, Ahvaz, Iran
}

Background: Melasma is a common benign acquired pigmentary dermatosis due to a disorder in the function of the melanogenesis process. Although several treatments are currently used, it remains a great challenge.

Aim: The aim of this study is to compare the efficacy of intradermal injected tranexamic acid (TA) vs hydroquinone (HQ) cream in the treatment of melasma.

Materials and methods: In this prospective split face controlled clinical trial, 49 patients were randomly divided into two groups of A ( 24 persons) and B (25 persons). Patients received TA intradermal injections every 2 weeks on the right side of the face with a concentration of $4 \mathrm{mg} /$ $\mathrm{mL}$ in group A and a concentration of $10 \mathrm{mg} / \mathrm{mL}$ in group B. The left side in both groups was treated twice daily with topical 4\% HQ cream, and treatment continued for 12 weeks in both groups. Melasma Area and Severity Index (MASI) scores were measured for each side of the face at baseline and at weeks $4,8,12$, and 24 . SPSS, version $22, P<0.05$, was used for data analysis. Results: Forty-one patients ( 21 in group A and 20 in group B) completed the study. The MASI score in the 12th week significantly decreased compared to the baseline for group A, group B, and HQ cream. However, no statistically significant difference was observed between the MASI score of patients in groups A and B. Also, the comparison of TA at the concentration of $4 \mathrm{mg} /$ $\mathrm{mL}$ compared to the $4 \%$ HQ cream showed that the MASI scores in the eighth week $(P=0.02)$ and the 12th week $(P=0.02)$ were significantly less in the HQ group. However, no significant difference was observed between the MASI score changes in Group B (10 mg/mL) and the 4\% HQ group. Also, patients in group A had higher satisfaction than patients in group $\mathrm{B}(P=0.001)$. Conclusion: Injection of TA intradermally can be an effective treatment for melasma. Keywords: melasma, tranexamic acid, hydroquinone, treatment

\section{Introduction}

Melasma is a common benign acquired pigmentary dermatosis due to a disorder in the function of the melanogenesis process. Melasma is often found as light to dark-brown patches and macules with irregular margins on the face symmetrically. ${ }^{1}$ Young women are often diagnosed with this disorder, and it occurs during pregnancy and hormonal changes in the ovaries. ${ }^{2}$ The main cause and pathogenicity of melasma is not yet clear, but it seems that the factors of genetic background, pregnancy, oral contraceptive pills, sunlight, ovarian tumors, hormone replacement therapy (HRT), and anticonvulsant drugs and steroids are involved in the onset of this disorder. ${ }^{3}$

In general, the treatment of melasma inhibits the production of pigment and the transfer of melanosomes into keratinocytes. Hydroquinone (HQ) cream acts as a
Correspondence: Maryam Zeynalie Dermatology Department, Emam Hospital, School of medicine, Ahvaz Jundishapur University Of Medical Science, Azadegan street, Ahvaz 6193673III, Iran

Email maryam_5988@yahoo.com 
standard treatment for various types of skin hyperpigmentation through inhibition of the enzyme affecting tyrosine oxidation (tyrosinase). Also, it can inhibit DNA and RNA synthesis reversibly and may also affect the production of melanosome. ${ }^{4}$ Other treatment modalities include: azelaic acid, 4-n-butylresorcinol and arbutin (tyrosinase inhibitor), kojic acid and ascorbic acid (interact with copper), retinoids (exfoliative agent), and corticosteroids (reduce underlying erythema). ${ }^{5,6}$ Furthermore, combination therapies including hydroquinone and retinoid and corticosteroids are used as the most effective treatments for melasma. Other therapeutic measures, such as chemical peeling and laser, are used for the treatment of resistant melisma..$^{5-7}$ Possible side-effects of these treatments include: erythema, irritation, sensitivity to sunlight, dryness, skin irritation, exogenous ochronosis, desquamation, atrophy, telangiectasia, hypertrichosis, and exanthema. ${ }^{7,8}$

Recently, trans-4-(Aminomethyl)cyclohexanecarboxylic acid, or tranexamic acid (TA), has been proposed as a new treatment for melasma. In 1979, Nijo Sadako accidentally discovered its effect during treatment of a patient with chronic urticaria. ${ }^{9}$ TA is a plasmin inhibitor, which is also considered a fibrinolysis inhibitor and can be used to reduce bleeding. TA is a synthetic derivative of the amino acid lysine and exerts its antifibrinolytic effect through the reversible blockade of lysine-binding sites on plasminogen molecules. It leads to the inhibition of the plasminogen activator from plasminogen transformation into plasmin. Plasminogen is also found in the basal layer of the human epidermis. ${ }^{10}$ The main mechanism of the hypopigmentant effects of TA is due to its antiplasmin activity. ${ }^{11}$ In addition, TA is similar to tyrosine in a portion of its structure, which can inhibit tyrosinase competitively. ${ }^{12}$ Also, Plasmin transforms the vascular endothelial growth factor (VEGF) into a diffusing form, and histological examination showed that TA plays an important role in the reduction of erythema and vascularities and the number of mast cell in the dermis. ${ }^{13,14}$ Various forms of TA are used orally, topically, and as a microinjection for the treatment of melasma. The amount of TA used to treat melasma is much less than the amount required for its antifibrinolytics effects. ${ }^{15}$

The present study aimed to use two concentrations of TA, 4 and $10 \mathrm{mg} / \mathrm{mL}$, and compare them with standard treatment (4\% HQ cream).

\section{Materials and methods Study type and population}

This prospective split face controlled clinical trial, from September 2017 to May 2018, included patients who were referred to the Dermatology Clinic of Imam Hospital of Ahvaz for the treatment of melasma and were willing to cooperate, women aged 18-50 years with bilateral symmetric melasma, who signed the consent form of the study, and were divided randomly in the basis of block permutation (four blocks) into two groups of A and B. It should also be noted that the exclusion criteria included pregnancy, lactation, oral contraceptive pills over the past 12 months, and during this study, any history of coagulation disorder and thrombotic problems, the use of anti-coagulant and anticonvulsant (phenytoin) drugs, sensitivity to the drug studied, the history of melasma treatment during the past month, herpes simplex lesions on the face, and ultimately patients with facial warts. This study was approved by the local Ethics committee of Ahvaz Jundishapur University of Medical Science, in accordance with the Declaration of Helsinki (code:IR.AJUMS.REC.1396.1091). All the patients signed the written informed consent form prior to initiation and for the images to be published.

\section{Implementation of this study}

During the first visit, each patient was examined by a Wood's lamp, and the type of melasma (epidermal, dermal, mixed) was determined. Also, if the lesion of the patient is exacerbated by the Wood's lamp, it is epidermal and otherwise dermal. If one part of the lesion was exacerbated and one part was unclear, it was considered as mixed. Then, the demographic characteristics of the patient, including age, sex, family history, precipitating factors, duration of melasma, previous treatments, skin phenotype, type of melasma, and affected areas, were recorded.

After taking a local anesthetic xyla-p cream (Tehran Shimi Pharmaceutical Co., Tehrean, Iran) on the right half of the face and dressing it for 1 hour, an intradermal injection of the TA (Caspian Tamin Pharmaceutical Co. Rasht, Iran) was performed using the insulin syringe and at intervals of $1 \mathrm{~cm}$. The right side of the face was injected intradermally with a concentration of $4 \mathrm{mg} / \mathrm{mL}$ in group A and $10 \mathrm{mg} / \mathrm{mL}$ in group B. Injection was done every 2 weeks. Also, the left side of the face of the patients in both groups was treated twice daily with $4 \% \mathrm{HQ}$ cream (Eldoquin Forte, ICN Company, Costa Mesa, California, USA) and all patients were recommended to use a sunscreen (with no pigment). The duration of treatment was 12 weeks.

\section{Preparation method and injection of tranexamic acid}

Tranexamic acid is available as a $5 \mathrm{~mL}$ vial containing $500 \mathrm{mg}$. An insulin syringe was used, with a volume of 
$1 \mathrm{~mL}$, containing $0.04 \mathrm{~mL}$ (4 units of insulin) of TA and the remainder being normal saline; thus each insulin syringe contains $4 \mathrm{mg}$ TA. In order to prepare the drug at a concentration of $10 \mathrm{mg}, 0.1 \mathrm{~mL}$ (10 units of insulin) of the TA was required to reach a volume of $1 \mathrm{~mL}$ with normal saline.

\section{Follow-up}

Patients follow-up was done by measuring the Melasma Area and Severity Index (MASI) score and evaluation of side-effects every 4 weeks (weeks $0,4,8$, and 12). MASI score was measured according to the standard guidelines (Figure 1). After completing treatment, patients were followed up 12 weeks later in order to evaluate the recurrence of melasma. Also, a general evaluation was done by the Dynamic Physician Global Assessment (Dynamic PGA) according to reduction in MASI score at the end of the treatment.

\section{Statistical methods of the analysis of results}

The one-way analysis of variance (ANOVA) and Tukey's test were used in order to compare the mean of quantitative variables in three groups. Kruskal-Wallis was used to compare the rank qualitative variables, and the square method was used to compare the nominal qualitative variables. T-pair test was also used before and after the test. Covariance analysis was also used in the case of the presence of an intervening variable. SPSS version $22, P<0.05$, was used and a significant level of 0.05 was considered.

\section{Results \\ Demographic and pre-intervention results}

Forty-one female patient completed the study. Eight patients discontinued the study (three from group A and five from group B); one patient developed urticaria upon TA injections, two patients because of the distance from the clinic, three because of disaffection from treatment, and no reason was stated by two patients. The mean age of the patients was $37.70 \pm 6.90$ years, and no significant difference was observed between the two groups $(P=0.28)$. The majority of patients $(46.3 \%)$ had Skin Type III, and the type of melasma among the majority of patients was epidermal (63.4\%). Patients characterization in two groups are summarized in Table 1. No statistically significant difference was observed between them, except the mean duration of the disease.

\section{Results of effectiveness of treatment with MASI score and dynamic physician global assessment}

Comparison of the mean MASI at baseline in group A (4 $\mathrm{mg} / \mathrm{mL})$ and group B $(10 \mathrm{mg} / \mathrm{mL})$ shows that no statistically significant difference was observed between them. Comparison of mean MASI score in group A compared to $4 \%$ HQ cream showed that no statistically significant difference was observed between the mean MASI score at baseline $(P=0.62)$ and the 4 th week $(P=0.34)$, but in the 8 th week $(P=0.02)$ and the 12 th week $(P=0.02)$, it was significantly less in the HQ cream $4 \%$ group. The mean MASI score in

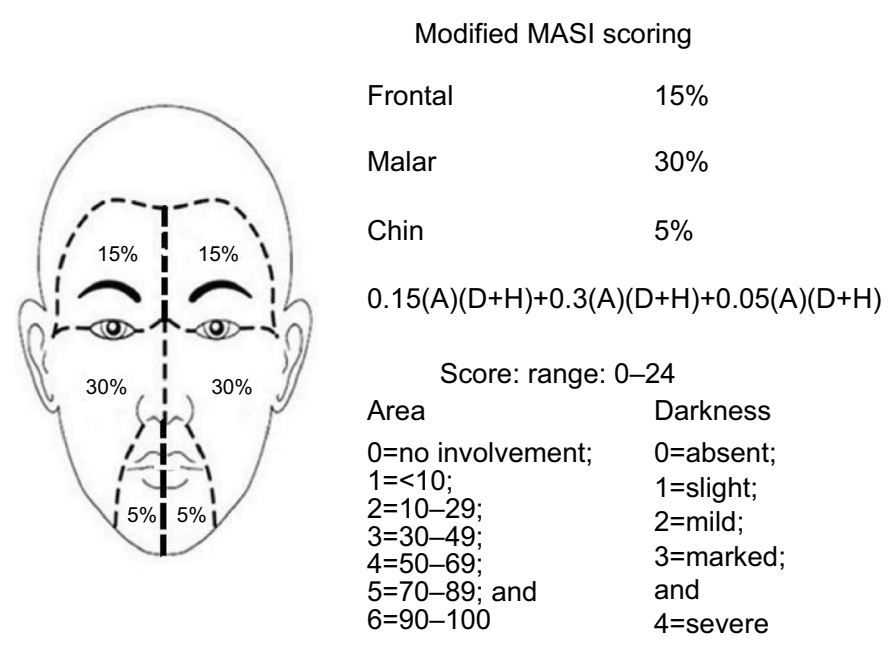

Figure I Modified MASI scoring

Abbreviation: MASI, Melasma Area and Severity Index. 
Table I Patients characterization in two groups

\begin{tabular}{|c|c|c|c|c|}
\hline \multicolumn{2}{|l|}{ Variables } & \multicolumn{2}{|l|}{ Group } & \multirow{2}{*}{\begin{tabular}{|l|}
$\boldsymbol{P}$-value \\
0.73 \\
\end{tabular}} \\
\hline \multirow[t]{4}{*}{ Skin type } & 2 & $\begin{array}{l}\begin{array}{l}\text { Group A } \\
\text { (\%) }\end{array} \\
\mathrm{I}(4.8)\end{array}$ & $\begin{array}{l}\text { Group B } \\
\text { (\%) } \\
3(15)\end{array}$ & \\
\hline & 3 & $10(47.6)$ & $9(45)$ & \\
\hline & 4 & $9(42.9)$ & $7(35)$ & \\
\hline & 5 & I (4.8) & I (5) & \\
\hline \multirow[t]{3}{*}{ Melasma type } & Mixed & $6(28.6)$ & $8(40)$ & \multirow[t]{3}{*}{0.39} \\
\hline & Epidermal & I5 (7I.4) & II (55) & \\
\hline & Dermal & $0(0)$ & I (5) & \\
\hline \multirow[t]{4}{*}{ Area affected } & Central & $0(0)$ & $2(10)$ & \multirow[t]{4}{*}{0.16} \\
\hline & Malar & $15(7 \mid .4)$ & $13(65)$ & \\
\hline & Central malar & $6(28.6)$ & $3(15)$ & \\
\hline & $\begin{array}{l}\text { Malar } \\
\text { mandibular }\end{array}$ & $0(0)$ & $2(10)$ & \\
\hline \multirow[t]{2}{*}{ Family history } & Yes & II (52.4) & II (55) & \multirow[t]{2}{*}{0.86} \\
\hline & No & $10(47.6)$ & $9(45)$ & \\
\hline \multirow{2}{*}{$\begin{array}{l}\text { Predisposing } \\
\text { factor }\end{array}$} & Pregnancy UV & I5 (7I.4) & $15(75)$ & \multirow[t]{2}{*}{0.79} \\
\hline & UV & $6(28.6)$ & $5(25)$ & \\
\hline \multirow{2}{*}{$\begin{array}{l}\text { Previous } \\
\text { treatment }\end{array}$} & Yes & $12(57.1)$ & $12(60)$ & \multirow[t]{2}{*}{0.85} \\
\hline & No & $9(42.9)$ & $8(40)$ & \\
\hline
\end{tabular}

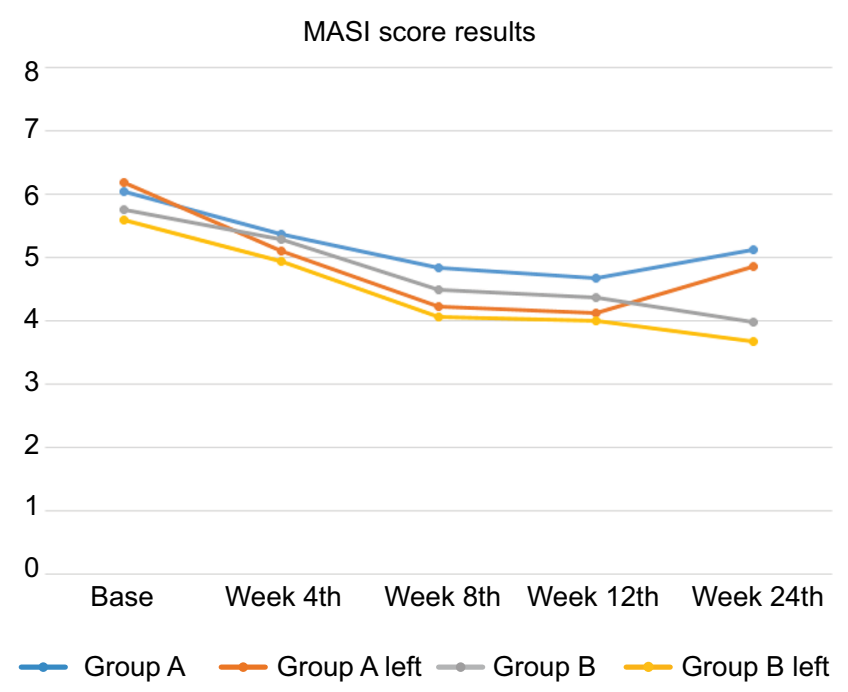

Figure 2 MASI score in two groups by right and left side results. Abbreviation: MASI, Melasma Area and Severity Index

group B compared to the 4\% HQ cream group showed that no statistically significant difference was observed in the mean MASI scores (Figure 2).

Also, the evaluation of reduction in MASI score by Physician Global Assessment showed that the comparison between groups $\mathrm{A}$ and $\mathrm{B}$ did not have a statistically significant difference $(P=0.99)$. However, comparison of Dynamic PGA in group A with the 4\% HQ cream shows PGA of the
HQ group was significantly better than group A $(P=0.031)$. Also, the comparison of Dynamic PGA in patients in group B with the 4\% HQ cream group did not show a statistically significant difference $(P=0.98)$ (Table 2).

\section{Satisfaction rate of patients}

Finally, patients' satisfaction rate data showed that patients in group A had a higher satisfaction rate than group B patients $(P=0.001)$, and patients in the hydroquinone group had a higher satisfaction rate than group $\mathrm{A}$, but no statistically significant difference was observed $(P=0.076)$. Finally, no statistically significant difference was observed between the satisfaction rate of group B compared to $4 \%$ HQ cream $(P=0.82)$ (Table 3).

\section{Adverse effects and relapse}

All patients experienced injection site burning pain, in spite of local anesthesia; one patient reported urticaria, who discontinued treatment. No adverse effect was seen in the HQ group.

Follow-up was done at 24 weeks, but only 19 patients (11 from A and 8 from B) returned. Six patients from group A and two from Group B relapsed.

\section{Discussion and conclusion}

Melasma is a common benign acquired dermatosis found by hyperpigmented macules or patches, most commonly on the face symmetrically. ${ }^{1}$ Studies have shown that melasma causes cosmetic disfigurement and leads to psychosocial distress. ${ }^{16}$

Treatment modalities for melasma include use of antisolar creams, hydroquinone, triple combination topicals, peeling, and laser. ${ }^{17} \mathrm{TA}$ has anti-plasmin activity, and this effect makes it a candidate for treatment of melasma, because plasmin has melanogenic and angiogenic properties. It has recently been discovered that the caliber and count of vascularity and expression of VEGF in melasma lesions increased, thereby showing that TA may clinically improve melasma by two mechanisms. In two review of the literature by Perper et al ${ }^{15}$ and Kim et a ${ }^{18}$ TA was indicated to be becoming a choice in treatment of melasma. However, there are scant studies that have assessed intradermal microinjection of TA as an effective and safe method. ${ }^{19-21}$ Previous studies had some disadvantages, mainly including lack of a control group. In 2006, Lee et al, ${ }^{19}$ during a prospective study, investigated the effect of localized TA intradermal microinjection (4 $\mathrm{mg} / \mathrm{mL}$ ) on 100 women with melasma. About 85 patients completed the study, and a statistically significant decrease was observed in MASI at 8 and 12 weeks. In another study 
Table 2 Dynamic PGA in two groups by right and left side results

\begin{tabular}{|l|l|l|l|l|l|l|l|l|l|l|}
\hline PGA & \multicolumn{2}{|l|}{ Excellent } & \multicolumn{2}{l|}{ Good } & Fair & Poor & P-value & P-value \\
\hline Groups & Number & Percent & Number & Percent & Number & Percent & Number & Percent & \\
\hline Group A & I & 4.8 & 4 & 19.0 & 3 & 14.3 & 13 & 61.9 & 0.031 & $0.99 *$ \\
\hline Group A left & 3 & 14.3 & 5 & 23.8 & 6 & 28.6 & 7 & 33.3 & \\
\hline Group B & I & 5.0 & 4 & 20.0 & 3 & 15.0 & 12 & 60.0 & 0.98 \\
\hline Group B left & I & 5.0 & 5 & 25.0 & 3 & 15.0 & 11 & 55.0 & \\
\hline
\end{tabular}

Notes: *P-value between groups A and B. Excellent ( $75 \%$ reduction in MASI). Good ( $5 \mathrm{I}-75 \%$ reduction in MASI). Fair (26-50\% reduction in MASI). Poor (0-25\% reduction in MASI).

Abbreviations: MASI, Melasma Area and Severity Index; PGA, Physician Global Assessment.

Table 3 Satisfaction in two groups by right and left side results

\begin{tabular}{|c|c|c|c|c|c|c|c|c|}
\hline \multirow{2}{*}{$\begin{array}{l}\text { Satisfaction } \\
\text { Groups }\end{array}$} & \multicolumn{2}{|l|}{ Relative } & \multicolumn{2}{|l|}{ No } & \multicolumn{2}{|c|}{ Complete } & \multirow[t]{2}{*}{$P$-value } & \multirow[t]{2}{*}{$P$-value } \\
\hline & number & percent & number & percent & number & percent & & \\
\hline Group A & 13 & 61.9 & 7 & 33.3 & I & 4.8 & \multirow[t]{2}{*}{0.07} & \multirow[t]{4}{*}{$<0.001 *$} \\
\hline Group A left & 18 & 85.7 & 3 & 14.3 & 0 & 0.0 & & \\
\hline Group B & 6 & 30.0 & 10 & 50.0 & 4 & 20.0 & \multirow[t]{2}{*}{0.82} & \\
\hline Group B left & 9 & 45.0 & 8 & 40.0 & 3 & 15.0 & & \\
\hline
\end{tabular}

Note: $* P$-value between groups $A$ and $B$.

in 2009 , Steiner et $\mathrm{al}^{20}$ compared the effects of topical TA $3 \%$ with intradermal injection of TA $(4 \mathrm{mg} / \mathrm{mL})$ in 18 women with melasma. Group A used 3\% TA twice a day and injection with TA $(4 \mathrm{mg} / \mathrm{mL})$ weekly for 12 weeks was performed for group B. Seventeen patients completed the study. According to MASI score and calorimetric evaluation, both groups improved significantly, and no significant difference was observed between them. In 2013, during a prospective study, Budamakuntla et $\mathrm{al}^{21}$ divided 60 patients into two groups. A group was under TA microinjection $(4 \mathrm{mg} / \mathrm{mL})$ and another group under TA microneedling $(4 \mathrm{mg} / \mathrm{mL})$ for 3 months $(0$, 4 , and 8 ) and followed-up for 3 months. In the microinjection group, $35.72 \%$ improvement was observed in MASI score, compared with $44.41 \%$ in the microneedling. Improvement in the microneedling group was better than the microinjection group. Elfar and El-Maghraby, ${ }^{22}$ in their study in 2015, treated 60 women in different ways to compare the effects of intradermal injection of TA ( 20 subjects) and silymarin cream as a strong antioxidant (20) and 50\% glycolic acid peeling (20). TA $(4 \mathrm{mg} / \mathrm{mL})$ was injected intradermally at intervals of $1 \mathrm{~cm}$ weekly for 12 weeks. Intradermal injection of tranexamic acid significantly reduced the MASI score from the baseline, but its effect was less than the silymarin cream and glycolic acid peeling. Sharma et al, ${ }^{23}$ during a study that ran during a period in in 2016, investigated 100 patients (92 women and eight men) and divided them into two groups. One group was treated with oral $250 \mathrm{mg}$ tranexamic acid twice a day and the other group was injected intradermally with TA $4 \mathrm{mg} / \mathrm{mL}$ every 4 weeks. The treatment period was
3 months. Mean reduction of MASI in the 12th week was 77.96 in the oral group and 79.00 in the injection group, so no significant difference was observed between them. In another prospective comparative study in 2018, Shetty and Shetty ${ }^{24}$ divided 40 patients into two group. Group A were treated with intradermal injection of TA $(4 \mathrm{mg} / \mathrm{mL})$ once at 3 week intervals $(0,3,6,9$, and 12 weeks) for 12 weeks and group B were treated with oral TA $250 \mathrm{mg}$ twice a day for 12 weeks. According to MASI score reduction, intradermal injection of TA has a higher clinical improvement (35.6\%) compared to oral TA $(21.7 \%)$. In our study, the MASI score in the 12th week significantly decreased compared to the baseline for group A, group B, and HQ cream. However, no statistically significant difference was observed between the MASI score in groups A and B. Also, $4 \mathrm{mg} / \mathrm{mL}$ TA compared to the $4 \%$ HQ cream showed that the MASI score in the eighth week $(P=0.02)$ and the 12 th week $(P=0.02)$ was significantly less in the HQ cream group. However, no significant difference was observed between the MASI score in Group B (10 $\mathrm{mg} / \mathrm{mL}$ ) and the $4 \%$ HQ cream group. Dynamic PGA evaluation showed that no statistically significant difference was observed between PGA in both groups A and B $(P=0.99)$. However, comparison between group $\mathrm{A}$ to $\mathrm{HQ}$ indicated that PGA of the HQ group was significantly better than group A $(P=0.031)$. Also, patients in group $\mathrm{A}$ had a higher satisfaction than patients in group $\mathrm{B}(P=0.001)$

Also, the review of other studies in the research community in Iran is consistent with the results of this study, for example, during a study in 2016, Saki et $\mathrm{al}^{25}$ investigated 37 
female patients with melasma, the right side of their faces was treated with $20 \mathrm{mg} / \mathrm{mL}$ TA injection monthly and the left side of their faces was treated with HQ cream $2 \%$ for 3 months. The melanin and erythema index was measured by a calorimetric device called Dermacch during the 4th, 8th, and 20th weeks. No significant difference was observed in the reduction of melanin index at the end of the follow-up period in both groups. As in the present study, tranexamic acid has no significant effect over the hydroquinone cream (Figures 3 and 4).

Intradermal injection of TA seems to be a safe treatment for melisma. Dose of TA and duration and interval of administration has been different in the previous study, but they all reported beneficial effects. The advantages of this study were the presence of the hydroquinone as the control group and higher concentration of TA; however, no difference was
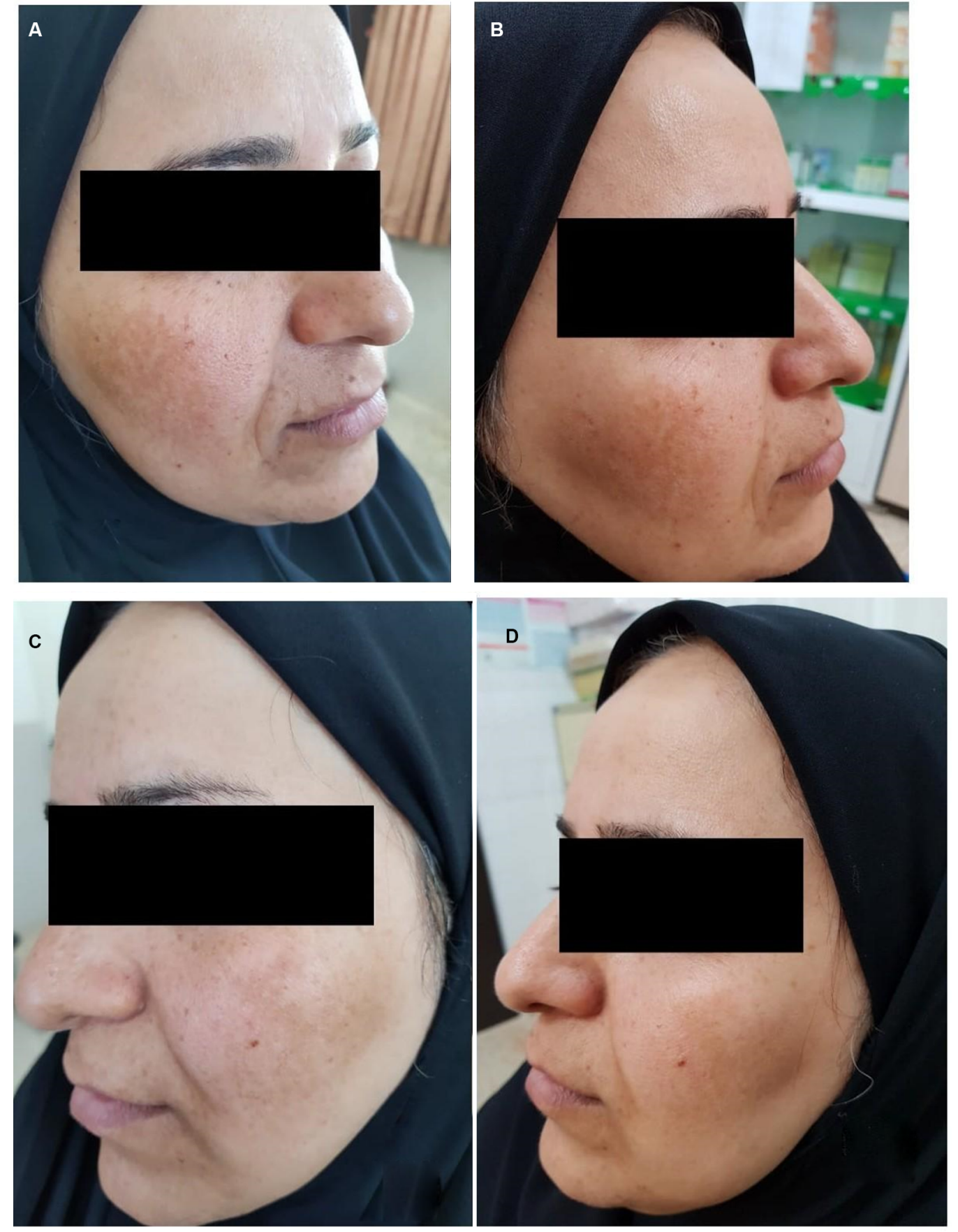

Figure 3 Before treatment with $4 \mathrm{mg} / \mathrm{mL}$ TA (A), after treatment with $4 \mathrm{mg} / \mathrm{mL}$ TA (B), before treatment with HQ (C), and after treatment with HQ (D). 

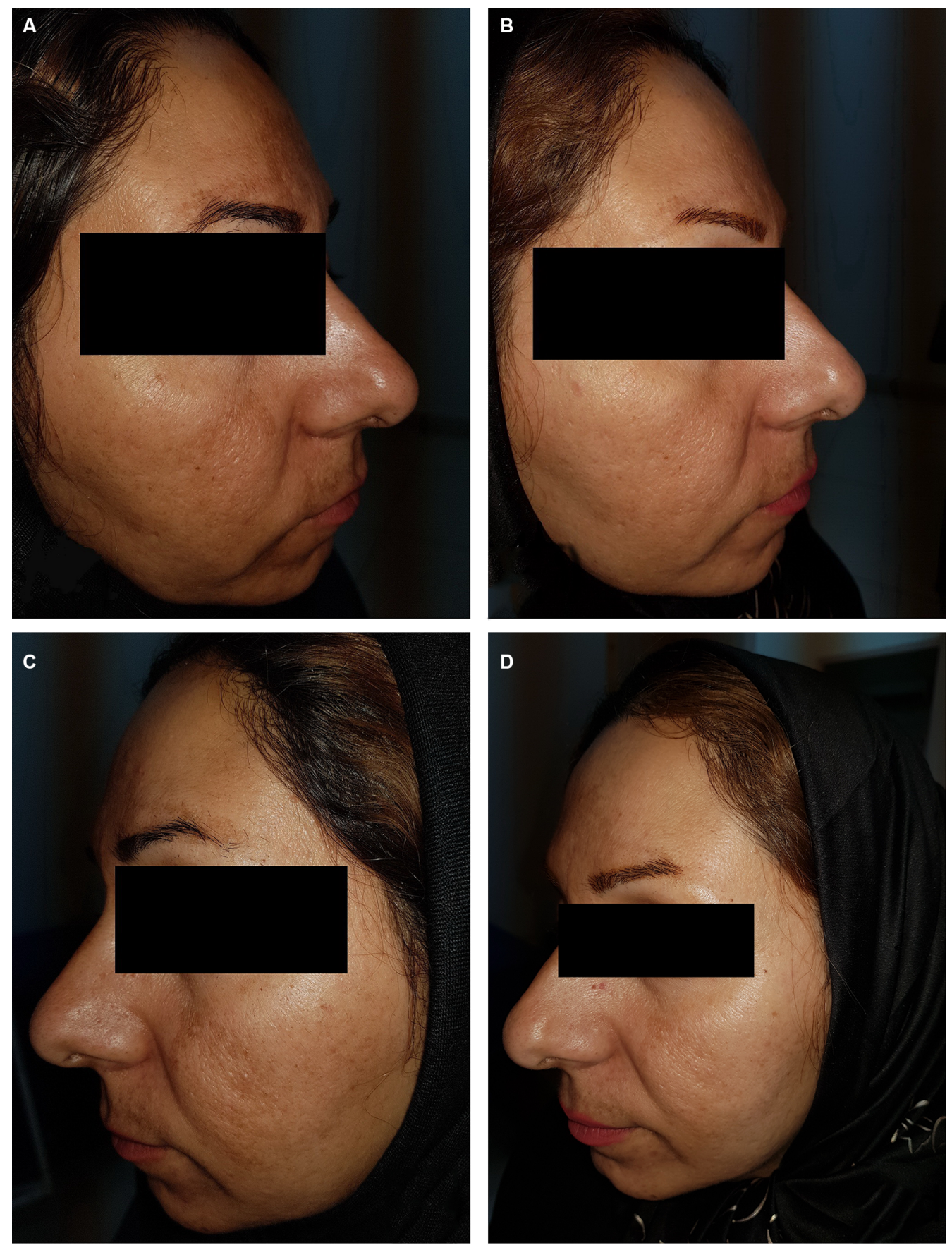

Figure 4 Before treatment with $10 \mathrm{mg} / \mathrm{mL}$ TA (A), after treatment with $10 \mathrm{mg} / \mathrm{mL}$ TA (B), before treatment with $\mathrm{HQ}$ (C), and after treatment with HQ (D).

observed between $4 \mathrm{mg} / \mathrm{mL}$ and $10 \mathrm{mg} / \mathrm{mL}$. Furthermore, compared to Sharma et al's ${ }^{23}$ study, mean reduction of MASI score in our study was lower. This may be due to many factors such as genetics, severity, duration and type of melasma, study design, etc.

The limitations of this study were the small number of participants, lack of blindness for the investigator, the inadequate duration of treatment and follow-up, and use of the MASI score, which is a subjective assessment method.
We suggest organizing studies to accentuate the optimum dose and duration of treatment with intradermal TA injection alone or in combination with other lightening agents.

\section{Data sharing statement}

Participants data, including demographic data and MASI scores, are available on request from the corresponding author, or can be obtained via http://www.IRCT.ir for up to 2 years after publication. 


\section{Acknowledgments}

This research article has been extracted from the thesis written by Dr Maryam Zeynalie conducted as a research project funded by the Research Deputy of Ahvaz Jundishapur University of Medical Sciences, Ahvaz, Iran (Registration No. D-3130).

\section{Disclosure}

The authors report no conflicts of interest in this work.

\section{References}

1. Miot LD, Miot HA, Silva MG, Marques ME. [Physiopathology of melasma]. An Bras Dermatol. 2009;84(6):623-635. Portuguese.

2. Gupta AK, Gover MD, Nouri K, Taylor S. The treatment of melasma: a review of clinical trials. J Am Acad Dermatol. 2006;55(6):1048-1065.

3. Elling SV, Powell FC. Physiological changes in the skin during pregnancy. Clin Dermatol. 1997;15(1):35-43.

4. Halder RM, Richards GM. Management of dyschromias in ethnic skin. Dermatol Ther. 2004;17(2):151-157.

5. Sheth VM, Pandya AG. Melasma: a comprehensive update: Part II. $J$ Am Acad Dermatol. 2011;65(4):699-714.

6. Kolbe L, Mann T, Gerwat W, et al. 4-n-butylresorcinol, a highly effective tyrosinase inhibitor for the topical treatment of hyperpigmentation. $J$ Eur Acad Dermatol Venerol. 2013;27(6 Suppl):19-23.

7. Shankar K, Godse K, Aurangabadkar S, et al. Evidence-based treatment for melasma: expert opinion and a review. Dermatol Ther (Heidelb). 2014;4(2):165-186.

8. Draelos ZD. Skin lightening preparations and the hydroquinone controversy. Dermatol Ther. 2007;20(5):308-313.

9. Sharma YK, Gupta A. Some other serendipitous discoveries in dermatology. Indian J Dermatol. 2016;61(1):95-96.

10. Tse TW, Hui E. Tranexamic acid: an important adjuvant in the treatment of melasma. J Cosmet Dermatol. 2013;12(1):57-66.

11. Ando H, Matsui MS, Ichihashi M. Quasi-drugs developed in Japan for the prevention or treatment of hyperpigmentary disorders. Int $J \mathrm{Mol}$ Sci. 2010;11(6):2566-2575.

12. Li D, Shi Y, Li M, Liu J, Feng X. Tranexamic acid can treat ultraviolet radiation-induced pigmentation in guinea pigs. Eur J Dermatol. 2010;20(3):289-292.
13. Kim EH, Kim YC, Lee ES, Kang HY. The vascular characteristics of melasma. J Dermatol Sci. 2007;46(2):111-116.

14. Na JI, Choi SY, Yang SH, Choi HR, Kang HY, Park KC. Effect of tranexamic acid on melisma: a clinical trial with histological evaluation. J Eur Acad Dermatol Venerol. 2013 (8):1035-1039.

15. Perper M, Eber AE, Fayne R. Tranexamic acid in the treatment of Melasma. Am J Clin Dermatol. 2017;18(3):373-381.

16. Ikino JK, Nunes DH, Silva VP, Fröde TS, Sens MM. Melasma and assessment of the quality of life in Brazilian women. An Bras Dermatol. 2015;90(2):196-200

17. Chai Q, Fei Y, Cao H, Wang C, Tian J, Liu J. Acupuncture for melasma in women: a systematic review of randomised controlled trials. Acupunct Med. 2015;33(4):254-261.

18. Kim HJ, Moon SH, Cho SH. Efficacy and safety of tranexamic acid in Melasma: a meta-analysis and systematic review. Acta Derm Venereol. 2017.

19. Lee JH, Park JG, Lim SH, et al. Localized intradermal microinjection of tranexamic acid for treatment of melasma in Asian patients: a preliminary clinical trial. Dermatol Surg. 2006;32(5):626-631.

20. Steiner D, Feola C, Bialeski N. Study evaluating the efficacy of topical and injected tranexamic acid in treatment of melasma. Surg Cosm Dermatol. 2009;1:174-177.

21. Budamakuntla L, Loganathan E, Suresh D, et al. A randomised, open-label, comparative study of tranexamic acid microinjections and tranexamic acid with microneedling in patients with melasma. $J$ Cutan Aesthet Surg. 2013;6(3):139-143.

22. Elfar NN, El-Maghraby GM. Efficacy of intradermal injection of tranexamic acid, topical silymarin and glycolic acid peeling in treatment of melasma: a comparative study. J Clin Exp Dermatol Res. 2015;06(03):3.

23. Sharma R, Mahajan VK, Mehta KS, Chauhan PS, Rawat R, Shiny $\mathrm{TN}$. Therapeutic efficacy and safety of oral tranexamic acid and that of tranexamic acid local infiltration with microinjections in patients with melasma: a comparative study. Clin Exp Dermatol. 2017;42(7): 728-734.

24. Shetty VH, Shetty M. Comparative study of localised intradermal microinjection of tranexamic acid and oral tranexamic acid for the treatment of melasma. Int J Res Dermatol. 2018;4(3):363-367.

25. Saki N, Darayesh M, Heiran A. Comparing the efficacy of topical hydroquinone $2 \%$ versus intradermal tranexamic acid microinjections in treating melasma: a split-face controlled trial. $J$ Dermatol Treat. 2018;29(4):405-410.
Clinical, Cosmetic and Investigational Dermatology

\section{Publish your work in this journal}

Clinical, Cosmetic and Investigational Dermatology is an international, peer-reviewed, open access, online journal that focuses on the latest clinical and experimental research in all aspects of skin disease and cosmetic interventions. This journal is included on PubMed. The manuscript management system is completely online

\section{Dovepress}

and includes a very quick and fair peer-review system, which is all easy to use. Visit http://www.dovepress.com/testimonials.php to read real quotes from published authors 